\title{
LA TRATA DE SERES HUMANOS CON FINES DE EXPLOTACIÓN LABORAL EN LA LEGISLACIÓN ESPAÑOLA
}

\author{
Autores: Josune López Rodríguez \\ josunelopezrodriguez@deusto.es \\ Universidad de Deusto \\ Francisco Javier Arrieta Idiakez \\ javier.arrieta@deusto.es \\ Universidad de Deusto
}

\begin{abstract}
Resumen
La trata de seres humanos con fines de explotación laboral aparece como un fenómeno impreciso e indeterminado en la legislación penal española que, tomando como referencia los instrumentos jurídicos internacionales y regionales por excelencia, se limita a mencionar un conjunto de términos con connotaciones laborales, pero sin definir su significado. Partiendo de estos antecedentes, el presente artículo tiene por objeto dotar de contenido a la expresión "explotación laboral" en el contexto de la trata de seres humanos, teniendo como base la legislación española.
\end{abstract}


Palabras clave: Trata de seres humanos; explotación laboral; delitos contra los derechos de los trabajadores; Código Penal.

\title{
Trafficking in human beings for labour exploitation within the spanish legislation
}

\begin{abstract}
Trafficking in human beings for labour exploitation appears as an imprecise and indeterminate phenomenon within the Spanish criminal legislation which, taking as a basis the international and regional legal instruments par excellence, only mentions a group of words with labour connotations, but without defining their meaning. From these premises, the main purpose of this article is to set the scope of the expression "labour exploitation" in the context of human trafficking, taking as a basis the Spanish legislation.
\end{abstract}

Key words: Trafficking in human beings; labour exploitation; crimes against the rights of workers; Criminal Code.

Fecha de recepción: 09/02/2019

Fecha de aceptación: 25/06/2019

\section{INTRODUCCIÓN}

La trata de seres humanos es un fenómeno con orígenes remotos que, durante siglos, ha estado amparado por leyes e instituciones oficiales. Ahora bien, la abolición oficial de la trata de esclavos y el reconocimiento universal de los derechos humanos no han conseguido erradicar la comercialización de seres humanos con fines de explotación.

Así, en pleno siglo XXI, esta práctica ilícita está adoptando manifestaciones y proporciones alarmantes que la convierten en uno de los principales retos actuales de la comunidad internacional. Este desafío ha sido incluido en la reciente Agenda 2030 para el Desarrollo Sostenible, aprobada mediante la Resolución de la Asamblea General de las Naciones Unidas de 25 de septiembre de 2015. En concreto, entre las metas específicas del Objetivo 8 -Trabajo decente y crecimiento económico-, se insta a los Estados a "adoptar medidas inmediatas y eficaces para [...] poner fin a las formas contemporáneas de esclavitud y la trata de personas". 
A grandes rasgos, la trata constituye un fenómeno realmente complejo que persigue la explotación de las personas y que supone, claramente, una grave violación de los derechos humanos más elementales. Tradicionalmente, la modalidad de trata que mayor difusión ha tenido en la opinión pública y que mayor atención ha recibido por parte de las instituciones es la que tiene por finalidad la explotación sexual de las víctimas, habiendo quedado relegadas a un segundo plano las demás formas de trata, entre las que cabe destacar aquella que persigue la explotación laboral de la víctima. En las últimas décadas, sin embargo, la comunidad internacional ha empezado a prestar atención a la trata con fines de explotación laboral. No obstante este reconocimiento oficial, lo cierto es que esta modalidad de trata sigue siendo desconocida para la sociedad.

Y es, precisamente, en esta forma de trata en la que se centra el presente artículo. Así, el objeto de este estudio consiste en analizar el alcance de la expresión "trata con fines de explotación laboral" a la luz de la legislación española. Para ello, primero, se expondrá el alcance conceptual de la trata de seres humanos en virtud del Código Penal; a continuación, se concretará el significado de la explotación laboral que deriva de un supuesto de trata de seres humanos; y, por último, se enumerarán las principales conclusiones del análisis realizado.

\section{LA TRATA DE SERES HUMANOS EN LA LEGISLACIÓN PENAL ESPAÑOLA}

La Ley Orgánica 5/2010, de 22 de junio, por la que se modifica la Ley Orgánica 10/1995, de 23 de noviembre, del Código Penal ${ }^{1}$, introdujo un Título ex novo en el texto penal (Título VII bis -De la trata de seres humanos-), dentro del Libro II, que contiene en su único artículo, a saber, el 177 bis, la tipificación del delito de trata de seres humanos. Este nuevo Título está ubicado a continuación del Título VII, en el que se tipifican los delitos de tortura y contra la integridad moral, lo que revela que los bienes jurídicos protegidos en el delito de trata son, fundamentalmente, la dignidad y libertad de la persona (Santana Vega, 2015, p. 652)․ A este último respecto, al protegerse un bien jurídico de naturaleza personalísima, el delito de trata de seres humanos "obliga a sancionar tantos delitos como víctimas, con arreglo a las normas que regulan el concurso real"3.

\footnotetext{
${ }^{1}$ BOE, de 23 de junio de 2010, núm. 152.

2 Vid. SAP de León, de 4 de diciembre de 2018, Sección 3ª , núm. rec. 20/2018, Fundamento de Derecho Segundo 1).

3 Acuerdo del Pleno No Jurisdiccional de la Sala Segunda del Tribunal Supremo de 31 de mayo de 2016. Asimismo, véanse las SSTS, Sala de lo Penal, Sección 1aㅡ, de 29 de enero de 2018, núm. rec. 739/2017, Fundamento de Derecho Primero, 1.2.4.; de 15 de marzo de 2017, núm. rec. 10648/2016,
} 
Mediante la inclusión de este nuevo Título en el texto penal, el legislador pretendió adaptar la normativa española a los convenios internacionales e instrumentos europeos suscritos por España en materia de trata de seres humanos y poner fin, al mismo tiempo, a los constantes conflictos interpretativos derivados de la redacción originaria del Código Penal en la que no se recogía mención alguna a este delito. Por un lado, en lo que se refiere a los compromisos adoptados por España en el momento de la reforma, deben destacarse el Protocolo para prevenir, reprimir y sancionar la trata de personas, especialmente mujeres y niños que complementa la Convención de las Naciones Unidas contra la Delincuencia Organizada Transnacional, hecho en Nueva York el 15 de noviembre de 2000 y ratificado por España el 21 de febrero de 2002 (Convenio de Palermo) ${ }^{4}$; la Decisión Marco 2002/629/JAI del Consejo, de 19 de julio de 2002, relativa a la lucha contra la trata de seres humanos ${ }^{5}$ y el Convenio 197 del Consejo de Europa sobre la lucha contra la trata de seres humanos, hecho en Varsovia el 16 de mayo de 2005 (Convenio de Varsovia) ${ }^{6}$. Por otro lado, con respecto a la confusión terminológica, la Comisión Europea destacó en el apartado de Conclusiones de su Informe, de 6 de diciembre de 2006, elaborado sobre la base del artículo 9 de la Decisión marco del Consejo, de 28 de noviembre de 20027, que las legislaciones penales de algunos Estados miembros (entre ellos, España), no establecían una distinción clara entre estos dos fenómenos.

Más recientemente, algunos de los apartados del artículo 177 bis han sido modificados por la Ley Orgánica 1/2015, de 30 de marzo, por la que se modifica la Ley Orgánica 1/1995, de 23 de noviembre, del Código Penal ${ }^{8}$. Precisamente, tal y como se explica en el apartado XXV de la Exposición de Motivos de la Ley Orgánica 1/2015, el delito de trata se tipificó antes de la entrada en vigor de la Directiva 2011/36/UE del Parlamento Europeo y del Consejo, de 5 de abril, relativa a la prevención y lucha contra la trata de seres humanos y a la protección de las víctimas y por la que se sustituye la Decisión marco 2002/629/JAI del Consejo9. La reforma del año 2010 tuvo en consideración el proyecto de Directiva, pero algunas cuestiones no fueron incluidas, de ahí la necesidad de introducirlas en esta nueva reforma para una completa transposición de la normativa europea ${ }^{10}$.

Fundamento de Derecho Cuarto; de 17 de junio de 2016, núm. rec. 10003/2016, Fundamento de Derecho Séptimo; de 3 de marzo de 2016, núm. rec. 10848/2014, Fundamento de Derecho Décimo, 2.C).

${ }^{4}$ BOE, de 11 de diciembre de 2003, núm. 296.

${ }^{5}$ DOCE, de 1 de agosto de 2002, núm. L 203

${ }^{6}$ BOE, de 10 de septiembre de 2009, núm. 219.

7 COM (2006) 770 final.

8 BOE, de 31 de marzo de 2015, núm. 77.

9 DOUE, de 15 de abril de 2011, núm. L 101.

${ }^{10}$ Consúltese la SAP de Valladolid, de 5 de diciembre de 2017, núm. rec. 19/2017, Fundamento de Derecho Segundo. 
Ello no obstante, lo cierto es que la mayoría de las modificaciones realizadas en el delito de trata obedecen "a la necesidad de introducir mejoras técnicas por imprecisiones que se habían detectado antes ya de la aprobación de la referida Directiva" (Villacampa Estiarte, 2017, pp. 452-453).

En la actualidad, el artículo 177 bis del Código Penal determina en su primer apartado que "será castigado con la pena de cinco a ocho años de prisión como reo de trata de seres humanos el que, sea en territorio español, sea desde España, en tránsito o con destino a ella, empleando violencia, intimidación o engaño, o abusando de una situación de superioridad o de necesidad o de vulnerabilidad de la víctima nacional o extranjera, o mediante la entrega o recepción de pagos o beneficios para lograr el consentimiento de la persona que poseyera el control sobre la víctima, la captare, transportare, trasladare, acogiere, o recibiere, incluido el intercambio o transferencia de control sobre esas personas, con cualquiera de las finalidades siguientes:

a) La imposición de trabajo o de servicios forzados, la esclavitud o prácticas similares a la esclavitud, a la servidumbre o a la mendicidad.

b) La explotación sexual, incluyendo la pornografía.

c) La explotación para realizar actividades delictivas.

d) La extracción de sus órganos corporales.

e) La celebración de matrimonios forzados.

Existe una situación de necesidad o vulnerabilidad cuando la persona en cuestión no tiene otra alternativa, real o aceptable, que someterse al abuso".

Concretamente, del concepto de trata recogido en el apartado mencionado se extrae la suma de elementos que integran la tipificación del delito del artículo 177 bis del texto penal, a saber: el elemento espacial; el elemento personal; el elemento comisivo; el elemento instrumental; y el elemento finalista.

(a) "Elemento espacial". Según la redacción del artículo 177 bis, la comisión del delito de trata de seres humanos debe guardar algún punto de conexión con el Estado español. Esto es, el delito de trata debe efectuarse en territorio español, desde España, en tránsito o con destino a ella. A este respecto, si bien el precepto pretende abarcar las situaciones de trata tanto internas como internacionales, lo característico es que el delito debe tener al territorio español como denominador común (Manzanares Samaniego, 2010, p. 215) ${ }^{11}$. Ahora bien, esta alusión expresa al ámbito geográfico en el tipo del delito no se corresponde con los instrumentos jurídicos internacionales y regionales, en los que no se incluye el elemen-

11 Véase la STS, Sala de lo Penal, Sección 1ª , de 3 de diciembre de 2013, núm. rec. 10587/2013, Fundamento de Derecho Sexto. 
to espacial. Teniendo en consideración que esta referencia contradice las disposiciones internacionales y regionales que comprometen al ordenamiento jurídico español, urge la subsanación de la misma. Al hilo de esta necesidad, se considera que el legislador español ha desaprovechado la última reforma operada en el Código Penal para realizar esta modificación y, en consecuencia, habrá que esperar a la próxima reforma del texto penal (Villacampa Estiarte, 2017, p. 461).

(b) "Elemento personal". Por un lado, el sujeto activo de este delito puede ser cualquier persona. Y, por otro lado, en lo que al sujeto pasivo se refiere, la víctima del delito de trata puede ser tanto "nacional" como "extranjera", pudiendo deducirse de esta puntualización que cualquier persona puede ser víctima de la trata ${ }^{12}$. Esta conclusión evidencia que la alusión explícita en el precepto a la nacionalidad de la víctima resulta insignificante y reiterativa y que responde, posiblemente, a la intención del legislador de matizar que el artículo 177 bis admite como sujetos pasivos tanto a las personas de nacionalidad española como a los extranjeros -ya estén en situación administrativa regular o irregular- (Villacampa Estiarte, 2011a, pp. 1115-1116). Debido a la irrelevancia de estos adjetivos y en aras de evitar confusiones innecesarias, se considera que los mismos deben ser suprimidos.

(c) "Elemento comisivo". Las conductas tipificadas en el artículo 177 bis son la captación, el transporte, el traslado, la acogida y la recepción de personas, incluido el intercambio o transferencia de control sobre las mismas, acción esta última introducida mediante la reforma de 2015. A este respecto, conviene matizar que el delito de trata se consuma cuando se realiza cualquiera de las acciones mencionadas mediante el empleo de alguno de los medios comisivos señalados infra-siempre que la víctima sea mayor de edad- y para conseguir cualquiera de los fines enumerados en el precepto, sin la necesidad de que se efectúen todas las conductas correspondientes a las sucesivas etapas (Sánchez-Covisa Villa, 2016, p. 40).

(d) "Elemento instrumental". El hecho delictivo tipificado en el artículo 177 bis debe efectuarse, siempre que el sujeto pasivo sea mayor de edad, recurriendo a alguno de los siguientes medios: violencia, intimidación, engaño, abuso de una situación de superioridad o de necesidad o de vulnerabilidad, o la entrega o recepción de pagos o beneficios para lograr el consentimiento de la persona que poseyera el control sobre la víctima. El último de los medios mencionados, que fue introducido por la Ley

12 SAP de Huesca, de 30 de diciembre de 2011, Sección 1ª̣, núm. rec. 3/2006, Fundamento de Derecho Segundo. 
Orgánica 1/2015, tiene una particularidad y es que, a diferencia de los demás medios comisivos, que recaen directamente sobre la víctima, este medio está relacionado con las personas que tienen el control sobre la víctima (Santana Vega, 2015, p. 656). Así, lo determinante de este nuevo medio comisivo no radica tanto en la propia entrega o recepción de pagos o beneficios sino en la existencia de una situación de control sobre la víctima "hasta el punto de poder disponer de ella como si fuera un mero objeto semoviente" (Sánchez-Covisa Villa, 2016, p. 43). A grandes rasgos, el empleo de cualquiera de estos medios invalida el consentimiento que la víctima mayor de edad hubiera podido $\operatorname{prestar}^{13}$. Según el apartado segundo del artículo 177 bis, la trata de menores de edad no implica el recurso a alguno de los medios enunciados (Arrieta Idiakez, Manrique López \& Manrique Rojo, 2011, pp. 289-290) ${ }^{14}$.

(e) "Elemento finalista". La trata de seres humanos, según el Código Penal español, debe perseguir cualquiera de los siguientes fines, estructurados en cinco grupos diferenciados: en primer lugar, "la imposición de trabajo o de servicios forzados, la esclavitud o prácticas similares a la esclavitud, a la servidumbre o a la mendicidad"; en segundo lugar, "la explotación sexual, incluyendo la pornografía"; en tercer lugar, "la explotación para realizar actividades delictivas"; en cuarto lugar, "la extracción de sus órganos corporales"; y, en quinto lugar, "la celebración de matrimonios forzados". Al hilo de esta distinción, pueden diferenciarse cinco modalidades distintas de trata en función de la finalidad perseguida en cada supuesto concreto, las cuales no tienen por qué presentarse de manera autónoma ya que suele ser habitual que las víctimas sean tratadas con distintos fines, a saber: la trata con fines de explotación laboral; la trata con fines de explotación sexual; la trata para la realización de actividades delictivas; la trata para la extracción de órganos corporales; y la trata para la celebración de matrimonios forzados (Sánchez-Covisa Villa, 2016, p. 44). En términos generales, estos fines "tienen como destino llevar a cabo el aprovechamiento de la persona, en el sentido más mercantil y cosificado de la expresión”"15.

${ }^{13}$ Este es, precisamente, el fundamento del apartado tercero del artículo 177 bis el cual determina que "el consentimiento de una víctima de trata de seres humanos será irrelevante cuando se haya recurrido a alguno de los medios indicados en el apartado primero de este artículo".

${ }_{14} \mathrm{Al}$ respecto, consúltense la STS, Sala de lo Penal, de 15 de diciembre de 2015, núm. rec. 10542/2015, Fundamento de Derecho Tercero (Recurso interpuesto por el acusado Alonso Gabriel), la SAP de Madrid, de 29 de junio de 2018, Sección 5ª , núm. rec. 4155/2016, Fundamento de Derecho Tercero y la SAP de Madrid, de 14 de abril de 2015, Sección 5ª, núm. rec. 15/2013, Fundamento de Derecho Tercero.

15 SAP de Oviedo, de 11 de enero de 2019, Sección 2ª , núm. rec. 6/2013, Fundamento de Derecho Tercero. 
Dicho esto, aunque el propósito de explotación debe estar presente desde el inicio, resulta necesario puntualizar que no es requisito que la explotación llegue a materializarse en la práctica (Maraver Gómez, 2011, p. 324). Precisamente, la trata es un delito de mera actividad, lo que supone que se consuma cuando se comete la acción típica y, por ende, no es necesario que se produzca la situación de explotación (Santana Vega, 2015, p. 655) ${ }^{16}$. De este modo, en el caso de producirse finalmente la explotación de la víctima, el delito de trata entrará en concurso con los delitos que conciernan a la correspondiente explotación (Sánchez-Covisa Villa, 2016, p. 41) ${ }^{17}$. Así lo reconoce, ciertamente, el apartado noveno del artículo 177 bis, en el que se determina que, "en todo caso, las penas previstas en este artículo se impondrán sin perjuicio de las que correspondan, en su caso, por el delito del artículo 318 bis de este Código y demás delitos efectivamente cometidos, incluidos los constitutivos de la correspondiente explotación".

Partiendo de estos cinco elementos, debe concluirse que, en términos generales, la trata de seres humanos constituye un proceso mediante el cual se persigue la explotación de las personas (Villacampa Estiarte, 2011b, p. 59). Más concretamente, a los efectos de la legislación penal española, la trata engloba la captación, el transporte, el traslado, la acogida y la recepción de una víctima nacional o extranjera, incluido el intercambio o transferencia de control sobre esas personas, en el territorio español, desde España, en tránsito o con destino a ella, empleando violencia, intimidación o engaño, o abusando de una situación de superioridad o de necesidad o de vulnerabilidad, o mediante la entrega o recepción de pagos o beneficios para lograr el consentimiento de la persona que poseyera el control sobre la víctima, siempre con una finalidad concreta que puede ser la imposición de trabajo o de servicios forzados, la esclavitud o prácticas similares a la misma, a la servidumbre o a la mendicidad; la explotación sexual, incluyendo la pornografía; la explotación para realizar actividades delictivas; la extracción de órganos corporales; o la celebración de matrimonios forzados.

16 STS, Sala de lo Penal, de 18 de mayo de 2016, núm. rec. 10791/2015, Fundamento de Derecho Tercero 2.2.

17 STSJ de Las Palmas de Gran Canaria, de 4 de diciembre de 2018, Sección 6ª , núm. rec. 71/2018, Fundamento de Derecho Segundo C.2. 


\section{LA EXPLOTACIÓN LABORAL COMO FINALIDAD DE LA TRATA DE SERES HUMANOS}

Una vez expuesto el concepto de trata de seres humanos comprendido en la legislación penal y mencionadas las modalidades predominantes, en el presente apartado se analizará el alcance de la trata que tiene por finalidad la explotación laboral de la víctima.

Pues bien, a grandes rasgos, la trata con fines de explotación laboral constituye una modalidad de trata indeterminada e imprecisa ya que ni la normativa internacional ni la normativa española se refieren expresamente a la misma. Es decir, la expresión "explotación laboral" no se recoge en ninguno de los instrumentos -internacionales, europeos y estatales- que tipifican esta práctica. En su defecto, los textos legales de referencia enumeran una serie de prácticas - "imposición de trabajo o de servicios forzados, la esclavitud o prácticas similares a la esclavitud, a la servidumbre o a la mendicidad"- como posibles fines laborales de la trata.

Ante la ausencia de una referencia explícita y definición de la "explotación laboral”, se considera necesario dotar de contenido a esta expresión para comprender su significado en el contexto de la trata. Para ello, primeramente, se prestará atención a los términos expresamente mencionados en el artículo 177 bis que pueden tener una dimensión laboral y, después, se verificará si los delitos contra los derechos de los trabajadores tipificados en el Código Penal se corresponden con las formas de explotación laboral recogidas en el apartado 1.a) del artículo 177 bis.

\section{LAS FORMAS DE EXPLOTACIÓN LABORAL MENCIONADAS EN EL ARTÍCULO 177 BIS}

La redacción actual del artículo 177 bis del Código Penal se fundamenta, en especial, en las disposiciones del Protocolo de Palermo, del Convenio de Varsovia y de la Directiva 2011/36/UE. Precisamente, en el apartado 1.a) del citado precepto, el legislador se ha limitado a transcribir los términos expuestos en dichos instrumentos como formas de explotación laboral vinculadas a la trata, pero sin precisar su significado (Pomares Cintas, 2011, p. 17).

Así, a grandes rasgos, puede deducirse que todos ellos se refieren a situaciones de sometimiento de las personas a trabajos o servicios en contra de su voluntad o sin su consentimiento legítimo (Pomares Cintas, 2013, p. 128). Teniendo en consideración que estos conceptos provienen de la normativa internacional, resulta necesario acudir a la misma en aras de delimitar su alcance en el marco de la legislación española. 


\subsection{La imposición de trabajo o de servicios forzados}

En virtud del Convenio número 29 de la Organización Internacional del Trabajo (OIT), sobre el trabajo forzoso, adoptado el 28 de junio de 1930, el trabajo forzoso u obligatorio comprende "todo trabajo o servicio exigido a un individuo bajo la amenaza de una pena cualquiera y para el cual dicho individuo no se ofrece voluntariamente". Años más tarde, esta definición fue ampliada por el Convenio número 105 de la OIT sobre la abolición del trabajo forzoso, de 1957, en el que se hizo alusión a la supresión de cinco casos concretos de trabajos forzosos ${ }^{18}$. Asimismo, recientemente, el Protocolo relativo al Convenio sobre el trabajo forzoso, aprobado en 2014 y en vigor desde 2016, ha reafirmado la definición contenida en el Convenio 29.

En concreto, esta noción está compuesta por un conjunto de características diversas cuya interpretación determinará su verdadero significado en la actualidad. Indudablemente, el alcance de esta expresión no puede basarse en una interpretación literal y textual de la misma, sobre todo, teniendo en cuenta que la elaboración del Convenio número 29 de la OIT se enmarca en un contexto histórico determinado que, precisamente, tenía por objeto reprimir la explotación de mano de obra en las colonias. Por consiguiente, se considera oportuno desglosar y comentar, por separado, los elementos que componen esta definición e interpretarlos a la luz de las circunstancias presentes.

(a) En primer lugar, la definición se refiere a un aspecto concreto de la vida del individuo, esto es, a la ejecución de un trabajo o de unos servicios (Sarasola Gorriti, 2009, p. 86). A este respecto, el Tribunal Europeo de Derecho Humanos ha manifestado que, actualmente, el término "trabajo" debe interpretarse en un sentido amplio y que, por ende, este abarca no solamente el trabajo de carácter manual sino cualquier trabajo o servicio $^{19}$. En este sentido, aunque las definiciones de los Convenios de la OIT se refieren explícitamente al "trabajo forzado u obligatorio", debe entenderse que la expresión "servicios forzados" también entra dentro

18 Concretamente, el artículo 1 determinaba la obligación de los Estados Miembros que ratificasen el Convenio de suprimir y no hacer uso de ninguna forma de trabajo forzoso u obligatorio en los siguientes supuestos:

a) como medio de coerción o de educación políticas o como castigo por no tener o expresar determinadas opiniones políticas o por manifestar oposición ideológica al orden político, social o económico establecido;

b) como método de movilización y utilización de la mano de obra con fines de fomento económico;

c) como medida de disciplina en el trabajo;

d) como castigo por haber participado en huelgas;

e) como medida de discriminación racial, social, nacional o religiosa.

19 Véase la STEDH, Van Der Mussele versus Bélgica, núm. 8919/80, de 23 de noviembre de 1983, párrafo 33. 
del alcance de las mismas. En relación con el alcance de este elemento, la OIT ha puntualizado que la naturaleza legal o ilegal de los trabajos o servicios en virtud de la legislación nacional aplicable en cada caso no limita la condición de trabajo o servicio forzado. Es más, no es necesario que una actividad esté reconocida como "actividad económica" para que pueda constituir una situación de trabajo o servicio forzoso (Organización Internacional del Trabajo, 2005, p. 7).

(b) En segundo lugar, dichos trabajos o servicios se caracterizan por ser forzados. Según el Tribunal Europeo de Derecho Humanos, este adjetivo manifiesta una idea de coacción física o psicológica sobre la persona ${ }^{20}$. Esto es, debe entenderse que el trabajo o el servicio se realiza "en condiciones determinadas de coacción” (Sarasola Gorriti, 2009, p. 86).

(c) En tercer lugar, esta forma de explotación implica la imposición de un trabajo o un servicio bajo la amenaza de una pena cualquiera, debiéndose interpretar la noción de "pena" en un sentido amplio ${ }^{21}$. Esta circunstancia vulnera, obviamente, uno de los elementos esenciales de las relaciones laborales reguladas por el Derecho del Trabajo, esto es, el trabajo libre (Rodríguez-Piñero y Bravo-Ferrer, 2011, p. 7). Precisamente, el trabajo objeto del Derecho del Trabajo se fundamenta en la prestación de un consentimiento previo, debiendo puntualizarse que dicha voluntariedad no se limita al acto de celebración del contrato de trabajo -que, por supuesto, tiene que concertarse de forma libre-, sino que se expande a otros aspectos de la vida de la relación contractual (Montoya Melgar, 2011, pp. 38-39). En concreto, este elemento engloba dos aspectos relevantes: la amenaza y la pena con la que se amenaza (García Sedano, 2018, p. 21).

Por un lado, la amenaza puede adoptar diferentes formas, a saber, puede ser física o psicológica. Al hilo de esta cuestión, la OIT reconoce que la amenaza más extrema es, posiblemente, aquella que implica violencia física o confinamiento e, incluso, la amenaza de muerte dirigida a la víctima o a sus familiares. Ahora bien, también explica que existen formas más sutiles de amenaza de carácter psicológico que son igualmente graves - por ejemplo, las amenazas de denuncia a la policía o a las autoridades de inmigración cuando la víctima está en una situación laboral ilegal- (Organización Internacional del Trabajo, 2005, p. 5$)^{22}$.

20 STEDH, Chowdury y otros versus Grecia, núm. 21884/15, de 30 de marzo de 2017, párrafo 90.

${ }^{21}$ STEDH, Tibet Mentes y otros versus Turquía, núms. 57818/10, 57822/10, 57825/10, 57827/10 y 57829/10, final de 24 de enero de 2018, párrafo 67 y STEDH, C.N. y V. versus Francia, núm. 67724/09, de 11 de octubre de 2012, párrafo 77.

22 A este respecto, consúltese la STEDH, C.N. and V. versus Francia, 11 de enero de 2013, párrafos 77-78. 
Por otro lado, la pena con la que se amenaza puede ser cualquiera. En realidad, el adjetivo "cualquiera" permite que la naturaleza de la pena con la que se amenaza no esté sujeta a limitación alguna. Al respecto, la OIT ha aclarado que la pena no tiene por qué consistir necesariamente en una sanción penal, sino que también puede suponer la pérdida de derechos y privilegios -verbigracia, cuando se amenaza al trabajador con el despido o con el impago de las remuneraciones si se niega a trabajar más horas de las fijadas en el contrato o en la legislación estatal aplicable- (Organización Internacional del Trabajo, 2007, p. 20). Es más, según el Tribunal Europeo de Derecho Humanos, la víctima no tiene por qué ser amenazada con una pena concreta, siendo suficiente que la misma sienta que ha sido penalizada o castigada como consecuencia de la severidad de la amenaza recibida ${ }^{23}$.

(d) En cuarto lugar, esta noción entraña la ausencia de consentimiento para realizar el trabajo o el servicio. En efecto, se entiende que existe consentimiento cuando éste se ha otorgado libremente; es decir, conociendo todos los elementos de la relación laboral y teniendo la posibilidad de revocar dicho consentimiento en cualquier momento (Huici Sancho, 2008, p. 73). De no darse estas circunstancias, se considerará que hay ausencia de consentimiento de la víctima.

En definitiva, la imposición de un trabajo o servicio forzoso supone un atentado contra la libertad de trabajar y contra el derecho al trabajo en condiciones dignas (Canosa Usera, 2005, p. 140). Además, este fenómeno constituye una violación grave de la dignidad de la persona y de otros derechos fundamentales de los que es titular -entre otros, el derecho a la intimidad, el derecho a no sufrir tratos inhumanos o degradantes, el derecho a la no discriminación- (Rodríguez-Piñero y Bravo-Ferrer, 2011, p. 19).

\subsection{La esclavitud y las prácticas similares a la esclavitud}

La Convención sobre la Esclavitud, de 1926, recogió la primera definición universal de la esclavitud, en base a la cual esta significa "el estado o condición de un individuo sobre el cual se ejercitan los atributos del derecho de propiedad o algunos de ellos" (cfr. artículo 1.1). Más adelante, con el fin de complementar y perfeccionar este primer texto, se aprobó la Convención suplementaria sobre la abolición de la esclavitud, la trata de esclavos y las instituciones y prácticas análogas a la esclavitud, hecha en Ginebra el 7 de septiembre de 1956, en la que

23 STEDH, Siliadin versus Francia, 26 de octubre de 2005, párrafo 118. 
se definió la esclavitud como "el estado o condición de las personas sobre las que se ejercen todos o parte de los poderes atribuidos al derecho de propiedad" [cfr. artículo 7.a)]. Claramente, estas definiciones responden a la acepción clásica de la esclavitud que engloba, por un lado, la noción de propiedad y, por otro lado, la idea de control sobre la persona (Vaz Cabral, 2006, p. 87) ${ }^{24}$. Sin embargo, en la actualidad, la utilización de los atributos del derecho de propiedad sobre otro ser humano es una práctica, en sí misma, ilegal (De Than \& Shorts, 2003, pp. 98-99).

En el marco jurídico actual, el Estatuto de Roma de la Corte Penal Internacional, de 17 de julio de 1998, define la esclavitud como "el ejercicio de los atributos del derecho de propiedad sobre una persona, o de alguno de ellos, incluido el ejercicio de esos atributos en el tráfico de personas, en particular mujeres y niños" [cfr. artículo 7.2.c)].

En esta línea, el Código Penal español se refiere a esta institución entre los delitos de lesa humanidad, como "la situación de la persona sobre la que otro ejerce, incluso de hecho, todos o algunos de los atributos del derecho de propiedad, como comprarla, venderla, prestarla o darla en trueque" (cfr. artículo 607 bis, apartado 2.10)].

Por su parte, la mencionada Convención suplementaria de 1956 identificó las situaciones que deben considerarse como prácticas análogas o equivalentes a la esclavitud, a saber: la servidumbre por deudas; la servidumbre de la gleba; el matrimonio por promesa, cesión o herencia; y la cesión de niños para el trabajo.

Teniendo en consideración estas definiciones, y adaptándolas al contexto vigente, puede concluirse que el elemento básico que caracteriza a la esclavitud actual y a las prácticas análogas a la misma es la "cosificación" de la persona, en tanto la persona explotadora mantiene una posición de dominio y control sobre la vida de la persona explotada, anulando su libertad y dignidad (Canosa Usera, 2005, p. 137; García Arán, 2006, pp. 9-10; y Sarasola Gorriti, 2009, p. 84). En la actualidad, este estado de dominación y sometimiento no tiene como presupuesto jurídico el ejercicio de los poderes propios del derecho de propiedad, ya que existe una prohibición jurídica universal al respecto; lo que se produce, en cambio, es una relación posesoria de carácter fáctico basada en el estado de necesidad en el que se encuentra la víctima (Baucells Lladós, 2006, p. 180, y Pérez Alonso, 2008, p. 63).

\subsection{La servidumbre}

Hasta el momento, ningún instrumento internacional ha definido el alcance de la servidumbre (Villacampa Estiarte, 2011b, p. 437). Ciertamente, fue la ya desaparecida Comisión Europea de Derechos Humanos la que, mediante el

\footnotetext{
${ }^{24}$ Ibídem, párrafo 122.
} 
estudio y revisión de su jurisprudencia y de las Convenciones internacionales sobre el trabajo forzoso, la esclavitud y las prácticas análogas a la misma, delimitó el concepto de esta práctica. Con base en las conclusiones de este organismo, la servidumbre conlleva la obligación de vivir y trabajar como propiedad de una tercera persona, realizando determinados servicios (retribuidos o no), sin poder abandonar o cambiar dicha condición (Bonet Pérez, 2017, p. 200 y Rodríguez-Piñero y Bravo-Ferrer, 2011, p. 10 $)^{25}$.

Asimismo, el Tribunal Europeo de Derecho Humanos ha destacado que la servidumbre constituye una forma "particularmente seria de negación de la libertad" 26 de una persona y que esta forma de explotación abarca "además de la obligación de proporcionar a otra persona ciertos servicios [...] la obligación para el siervo de vivir en la propiedad de otra persona y la imposibilidad de cambiar su condición" $"$ ?

A partir de lo expuesto, puede concluirse que la concepción jurídica de la servidumbre se refiere al estado en el que se encuentra una persona y a su consecuente condición de vida (Robertson \& Merrills, 1993, p. 47), o, dicho de otro modo, esta noción se refiere a la "situación de la persona completamente sometida a alguien o algo, o entregada a su servicio" ${ }^{28}$. En este sentido, la persona es obligada a prestar cualquier tipo de servicio en contra de su voluntad, quedando su libertad de acción restringida y limitada (Villacampa Estiarte, 2011b, p. 438). Evidentemente, esta es una noción muy genérica que puede englobar una multitud de situaciones diferentes, entre otras, las prácticas o conductas análogas a la esclavitud a las que se refería la Convención suplementaria de 1956, esto es, la servidumbre por deudas y la servidumbre de la gleba (Rodríguez-Piñero y Bravo-Ferrer, 2011, pp. 9-10).

\subsection{La mendicidad}

El artículo 177 bis del Código Penal incluye la mendicidad como uno de los fines de explotación laboral a los que puede conducir la trata. En el momento en el que el legislador español introdujo esta forma de explotación entre los fines de la trata, esta práctica no se recogía en ninguno de los instrumentos de referencia en materia de trata. Poco después de la reforma del Código Penal de 2010, la Directiva 2011/36/UE se refirió expresamente a esta forma de explotación de la siguiente forma: "la explotación incluirá, como mínimo, [...], el trabajo o los

${ }^{25}$ Ibídem, párrafo 104.

26 STEDH, Van Droogenbroeck versus Bélgica, núm. 7906/77, de 24 de junio de 1982, párrafo 58.

27 STEDH, Siliadin versus Francia, núm. 73316/01, de 26 de octubre de 2005, párrafo 123.

28 SAP de Albacete, de 25 de noviembre de 2011, Sección 2a , núm. rec. 17/2016, Fundamento de Derecho Primero. 
servicios forzados, incluida la mendicidad [...]" (cfr. artículo 2.3). Esto es, la normativa europea estableció una vinculación entre la mendicidad y los trabajos o servicios forzados.

A grandes rasgos, la práctica de la mendicidad consiste en mendigar por las calles o a las puertas de los establecimientos -conocida como "mendicidad callejera"-; pero, también puede radicar en el desarrollo de actividades como, por ejemplo, la venta de baratijas, la venta de pañuelos de papel o la limpieza de los limpiaparabrisas de los vehículos - denominada "mendicidad encubierta"- (Villacampa Estiarte, 2011b, p. 77).

En este sentido, para que la mendicidad sea considerada como forma de explotación laboral, esta debe presentar naturaleza laboral y debe englobar, además, la imposición de condición de trabajador y la disponibilidad respecto de la persona para quien se efectúa el servicio (Pomares Cintas, 2013, pp. 134-135). De algún modo, esta actividad explotadora presenta unas características similares a las prácticas expuestas en los apartados precedentes, por lo que su referencia expresa se podría haber omitido.

\section{LAS FORMAS DE EXPLOTACIÓN LABORAL TIPIFICADAS EN EL CÓDIGO PENAL: ¿CONCORDANCIA CON LAS FINALIDADES DE LA TRATA?}

Tal y como se ha avanzado supra, la trata es un delito de consumación anticipada, por lo que de materializarse la finalidad última de la trata, esta entrará en concurso con los delitos que correspondan a la situación de explotación (Sánchez-Covisa Villa, 2016, p. 40).

En concreto, en lo que se refiere a la materialización de la explotación laboral, debe avanzarse que, entre las finalidades mencionadas en el apartado 1.a) del artículo 177 bis, el Código Penal solamente tipifica de manera autónoma la utilización de menores o personas con discapacidad necesitadas de especial protección para la práctica de la mendicidad (cfr. artículo 232.1) y la esclavitud como delito de lesa humanidad, es decir, como parte de un ataque generalizado o sistemático contra la población civil o contra una parte de ella (cfr. artículo 607 bis, apartado $2.10)^{29}$. Por consiguiente, en los supuestos en los que la finalidad de explotación laboral no encaje en estos preceptos, será complejo resolver el concurso de delitos (López Rodríguez, 2016, p. 172).

Pues bien, el Código Penal tipifica en el Título XV del Libro II, bajo la rúbrica -De los delitos contra los derechos de los trabajadores-, una serie de delitos

\footnotetext{
29 Al respecto, vid. SAP de Valencia, de 12 de marzo de 2019, Sección 3aㅗ , núm. rec. 73/2018, Fundamento de Derecho Cuarto A).
} 
laborales que pueden considerarse como formas de explotación laboral. Ahora bien, lo que debe dilucidarse es si estos delitos se corresponden con las formas de explotación laboral severa recogidas en el artículo 177 bis. A tal fin, a continuación se analizará el alcance de los delitos contra los derechos de los trabajadores tipificados en los artículos 311, 311 bis y 312.2 , segundo inciso, con el fin último de solventar la cuestión descrita.

\subsection{Artículo 311 (apartados primero y cuarto)}

Conforme a la tipificación de este delito en el artículo 311 del Código Penal, se castiga con las penas de prisión de seis meses a seis años y multa de seis a doce meses a quienes "mediante engaño o abuso de situación de necesidad, impongan a los trabajadores a su servicio condiciones laborales o de Seguridad Social que perjudiquen, supriman o restrinjan los derechos que tengan reconocidos por disposiciones legales, convenios colectivos o contrato individual" (cfr. apartado primero). Además, si estas conductas se llevan a cabo con violencia o intimidación se impondrán las penas superiores en grado (cfr. apartado cuarto).

En concreto, "el verbo definidor del tipo penal es el de «imponer»", debiendo entenderse por tal "la existencia de una situación que suprima la capacidad de reacción indispensable para que el perjudicado reaccione en defensa de sus derechos que ve perjudicados" 30 . Ciertamente, "se trata de una situación situada extramuros de los conceptos jurídicos de violencia o intimidación" ${ }^{31}$ que, de concurrir, integrarían el subtipo agravado del apartado cuarto del artículo 311.

En relación con el elemento comisivo de este delito, deben analizarse, aunque sea de forma sucinta, los atributos complementarios requeridos para llevar a cabo la acción principal consistente en "imponer" las siguientes condiciones (De Vicente Martínez, 2008, pp. 215-218, y Hortal Ibarra, 2015, p. 1100).

(a) Condiciones laborales. Entendiendo estas condiciones en sentido amplio, deben quedar comprendidas entre las mismas todas aquellas que constituyen el contenido de la relación de trabajo, es decir, todas las que afectan a la celebración, ejecución y cumplimiento del contrato.

(b) Condiciones de Seguridad Social. Estas son todas las derivadas de la relación jurídica básica de protección inherente al Sistema Público de Seguridad Social, atinentes, por tanto, a las relaciones jurídicas instrumentales de encuadramiento (afiliación, altas, bajas, modificación de datos perjudiciales para los derechos de los trabajadores), de cotización (inexistencia

30 STS, Sala de lo Penal, de 5 de abril de 2017, Sección 1ª , núm. rec. 1087/2016, Fundamento de Derecho Tercero.

${ }^{31}$ Ibídem. 
o descubiertos de cotizaciones) y de protección. Pero, al mismo tiempo, también deben considerarse las condiciones derivadas de la Seguridad Social Complementaria, establecidas vía negociación colectiva, y consistentes, básicamente, en mejoras voluntarias y planes y fondos de pensiones.

A este respecto, huelga recordar que el elemento comisivo descrito debe materializarse por medio de los elementos instrumentales de engaño o abuso de situación de necesidad, viéndose la pena agravada cuando se recurra a la violencia o intimidación ${ }^{32}$.

En esencia, el apartado primero del artículo 311 tiene por objeto proteger las condiciones laborales mínimas a las que no pueden renunciar los trabajadores (Hortal Ibarra, 2015, p. 1100), de acuerdo con el artículo 3.5 del Real Decreto Legislativo 2/2015, de 23 de octubre, por el que se aprueba el texto refundido de la Ley del Estatuto de los Trabajadores ${ }^{33}$.

\subsection{Artículo 311 bis}

Este precepto, introducido en el Código Penal por la Ley Orgánica 1/2015, determina que "será castigado con la pena de prisión de tres a dieciocho meses o multa de doce a treinta meses, salvo que los hechos estén castigados con una pena más grave en otro precepto de este Código, quien: a) de forma reiterada, emplee o dé ocupación a ciudadanos extranjeros que carezcan de permiso de trabajo, o b) emplee o dé ocupación a un menor de edad que carezca de permiso de trabajo". Resulta paradójico, sin embargo, que el legislador no haya hecho referencia a la vulneración de los derechos laborales que legitime la intervención del Derecho penal como máxima expresión del ius puniendi, convirtiendo, así, en delito un ilícito administrativo (Hortal Ibarra, 2015, pp. 1105-1106).

Por un lado, este artículo sanciona a quien de manera reiterada emplee o dé ocupación a ciudadanos extranjeros sin permiso de trabajo. La utilización de los verbos "emplear" y "dar ocupación" de manera alternativa plantea dos interpretaciones posibles, a saber: concluir que ambos constituyen comportamientos diferentes o entender que son conductas sinónimas. El legislador tampoco ha precisado el alcance de la expresión "de forma reiterada" (Hortal Ibarra, 2015, p. 1106). Y, por otro lado, el artículo 311 bis sanciona a quien emplee o dé ocupación a un menor de edad que carezca de permiso de trabajo. En este segundo supuesto, no se exige que la conducta se realice "de forma reiterada".

32 Vid. STS, Sala de lo Penal, de 9 de junio de 2016, Sección 1ª , núm. rec. 2171/2015, Fundamento de Derecho Primero.

${ }^{33}$ BOE, de 24 de octubre de 2015, núm. 255. 
En suma, se considera que este tipo penal es "redundante y distorsionador" y que, además, no resulta óptimo "para incriminar casos de efectiva esclavización" (Villacampa Estiarte, 2014, p. 15).

\subsection{Artículo 312.2, segundo inciso}

En virtud del artículo 312.2, segundo inciso, se castigan con las penas de prisión de dos a cinco años y multa de seis a doce meses a quienes "empleen a súbditos extranjeros sin permiso de trabajo en condiciones que perjudiquen, supriman o restrinjan los derechos que tuviesen reconocidos por disposiciones legales, convenios colectivos o contrato individual".

En efecto, este constituye un tipo específico sólo aplicable cuando el sujeto pasivo es una persona extranjera sin autorización de trabajo. A diferencia del artículo 311.1, en el que se exige el recurso al engaño o abuso de situación de necesidad, en este caso no se requiere el empleo de dichos medios, ello porque "el legislador consideró que la contratación de un trabajador extranjero sin permiso de trabajo lleva ínsita la actuación engañosa y el aprovechamiento por parte del empresario de una situación de ilegalidad a fin de imponerle tales condiciones ilegales de trabajo" 34 .

Dicho esto, debe entenderse que para la aplicación del tipo penal descrito se requiere que la acción nuclear del tipo - la contratación de una persona extranjera sin autorización de trabajo- perjudique, suprima o restrinja, materialmente, los derechos que tengan reconocidos por disposiciones legales, convenios colectivos o contrato individual, más allá del mero aprovechamiento de la situación de necesidad genérica de las personas inmigrantes sin permiso de trabajo ${ }^{35}$. En definitiva, "debe suponer el empleo del extranjero en condiciones de indignidad" (Lascuraín Sánchez, 2007, p. 899, y Valle Muñiz \& Villacampa Estiarte, 2004, p. 1606), privándole "de los derechos que el Estatuto de los Trabajadores considera irrenunciables" ${ }^{\prime 36}$.

Asimismo, resulta oportuno señalar que existe un importante matiz en comparación con el artículo 311.1, al referirse el artículo 312.2, segundo inciso, de forma genérica a las "condiciones", y no a las "condiciones laborales y de Seguridad Social", de los extranjeros sin autorización de trabajo (Vieira Morante, 2007, pp. 2351-2352). A este respecto, la doctrina ha entendido que dichas "condiciones" Segundo.

34 SAP de Ceuta, de 13 de enero de 2000, Sección 6ª̣, núm. rec. 112/1999, Fundamento de Derecho

${ }^{35} \mathrm{Al}$ respecto, vid. STS, Sala de lo Penal, de 12 de diciembre de 2005, Sección $1^{\underline{a}}$, núm. rec. 1942/2004, Fundamento de Derecho Tercero.

36 STS, Sala de lo Penal de 8 de marzo de 2004, Sección 1ª , núm. rec. 449/2003, Fundamento de Derecho Cuarto, 2. 
se refieren a las "condiciones laborales" en idénticos términos a los comentados supra en torno al artículo 311.1 (Barrios Baudor \& Quintanilla Navarro, 2011, p. 99; De Vicente Martínez, 2008, pp. 337-338; Pomares Cintas, 2013, p. 114). Ahora bien, los problemas surgen al preguntarse qué ocurre con las condiciones de Seguridad Social de los trabajadores extranjeros irregulares afectados por el tipo del 312.2, segundo inciso. Esto es, ipodrá entenderse también que el empresario puede emplear a sus trabajadores en condiciones de Seguridad Social que perjudiquen, supriman o restrinjan los derechos que tuvieran reconocidos por disposiciones legales, convenios colectivos o contrato individual?

En principio, teniendo en consideración que para que los extranjeros se incorporen formal y regularmente al Sistema de Seguridad Social español se requiere previamente la obtención de la autorización de trabajo y residencia ${ }^{37}$, es indiscutible que los extranjeros irregulares no cumplen los requisitos de acceso al Sistema, por lo que no es posible estimar válidos los actos de encuadramiento -afiliación y alta- ni la cotización de los mismos.

No obstante, a los efectos de protección, respecto a las contingencias derivadas de los riesgos profesionales -accidentes de trabajo y enfermedades profesionales-, es decir, incapacidad temporal, incapacidad permanente y muerte y supervivencia, se produce una ficción jurídica de inclusión en el Sistema de todos los extranjeros, regulares e irregulares (Navas-Parejo Alonso, 2010, p. 199). En este sentido, el empresario, ante el acaecimiento de un accidente de trabajo o enfermedad profesional de un trabajador extranjero irregular incurrirá en el delito tipificado en el artículo 312.2, segundo inciso. Es más, dado que a los solos efectos de las contingencias derivadas de los riesgos de accidentes de trabajo y enfermedades profesionales los trabajadores inmigrantes irregulares se considerarán incluidos en el Sistema, éstos podrán exigir a la entidad gestora correspondiente el anticipo de las prestaciones, en virtud del principio de automaticidad de las prestaciones, sin perjuicio de su posterior repetición contra el empresario responsable. Y, por el mismo motivo, también responderán subsidiariamente las entidades gestoras en los casos de insolvencia empresarial. En este sentido, la Seguridad Social deberá conceder siempre las correspondientes prestaciones, pero su coste acabará repercutiendo siempre en el empresario a través del Derecho administrativo sancionador.

37 Así se deduce de los artículos 10.1 y 36.1 de la Ley Orgánica 4/2000, de 11 de enero, sobre derechos y libertades de los extranjeros en España y su integración social, del artículo 7.1 del Real Decreto legislativo 1/1994, de 20 de junio, por el que se aprueba el Texto Refundido de la Ley General de la Seguridad Social (BOE, de 29 de junio de 1994, núm. 154) y del artículo 42.1 del Real Decreto 84/1996, de 26 de enero, por el que se aprueba el Reglamento General sobre inscripción de empresas y afiliación, altas, bajas y variaciones de datos de trabajadores en la Seguridad Social (BOE, de 27 de febrero de 1996, núm. 50). 
Y, en relación con las contingencias no derivadas de riesgos profesionales, en teoría, también puede predicarse la protección de los trabajadores inmigrantes irregulares, aunque se trate éste de un derecho limitado en todas sus dimensiones: el procedimiento de reclamación, el sujeto responsable o, incluso, el tipo de prestaciones que podrán reclamarse (González Ortega, 2010, p. 251). Ciertamente, el título jurídico habilitante para la protección se encuentra en la nueva redacción dada tras la reforma de 2009 al artículo 36.5 de la Ley Orgánica 4/2000, de 11 de enero, sobre derechos y libertades de los extranjeros en España y su integración social ${ }^{38}$, aunque su dicción no sea tan clara como debiera serlo. Así, se determina que la carencia de la autorización de residencia y trabajo no será obstáculo para la obtención por el trabajador inmigrante de las prestaciones derivadas de supuestos contemplados por los convenios internacionales de protección a los trabajadores u otros que pudieran corresponderle, siempre que sean compatibles con su situación. Del mismo modo, dicha disposición viene a complementar lo establecido por el tercer párrafo del artículo 42.2 del Real Decreto 84/1996, de 26 de enero, por el que se aprueba el Reglamento General sobre inscripción de empresas y afiliación, altas, bajas y variaciones de datos de trabajadores en la Seguridad Social ${ }^{39}$, al señalar que los extranjeros que, precisando de autorización administrativa previa para trabajar, desempeñen una actividad en España careciendo de dicha autorización, no estarán incluidos en el Sistema de Seguridad Social, sin perjuicio de que puedan considerarse incluidos a efectos de la obtención de determinadas prestaciones "de acuerdo con lo establecido en la ley".

En la práctica, sin embargo, la persona extranjera en situación administrativa irregular se encontrará con importantes obstáculos para hacer efectivo su derecho de protección, pues, precisamente, deberá probar determinadas circunstancias de hecho, como su trabajo asalariado, en el momento de materializarse la contingencia, y que lleva trabajando un tiempo mínimo determinado, equivalente al período de carencia exigido a los ciudadanos que sí se encuentran en el Sistema de Seguridad Social. Además, para conseguir el reconocimiento de las prestaciones por la correspondiente contingencia, deberá acudir a la entidad gestora adecuada que deberá actuar a los solos efectos de constatar la existencia o no de la contingencia, con posibilidad de impugnar, en su caso, la resolución negativa en el orden jurisdiccional social. Nótese que al contrario de lo que sucede para con las contingencias derivadas de riesgos profesionales, aquí no existe ninguna ficción que conlleve la inclusión de los trabajadores inmigrantes irregulares en el Sistema.

${ }^{38}$ BOE, de 12 de enero de 2000, núm. 10.

39 BOE, de 27 de febrero de 1996, núm. 50. 
Asimismo, debe entenderse incluido en el tipo del artículo 312.2, segundo inciso, la Seguridad Social complementaria de carácter voluntario, que en la mayoría de los casos se articula vía convenio colectivo.

\section{4. ¿Se corresponden los delitos contra los derechos de los trabajadores con las formas de explotación laboral contempladas en el artículo 177 bis?}

A partir de lo expuesto, puede deducirse que los delitos tipificados en los artículos 311 y 312.2, segundo inciso, del Código Penal, se refieren al establecimiento de condiciones laborales y sociales contrarias a la normativa social y laboral y que el delito contenido en el artículo 311 bis alude al empleo u ocupación de personas extranjeras o menores de edad sin autorización para trabajar. Ahora bien, a diferencia de las formas de explotación laboral contenidas en el artículo 177 bis, que se caracterizan por la imposición de trabajos o servicios, los delitos contra los derechos de los trabajadores no conllevan la imposición de la propia prestación de trabajo (Pomares Cintas, 2013, p. 139). Además, puede percibirse que mientras los delitos contra los derechos de los trabajadores atentan contra los derechos laborales o sociales de los trabajadores, las formas de explotación laboral comprendidas en el artículo 177 bis vulneran la dignidad y libertad humanas.

Por estas razones, cabe concluir que los delitos contra los derechos de los trabajadores no se corresponden con las formas de explotación laboral enumeradas en el aparado 1.a) del artículo 177 bis del Código Penal. Como consecuencia, resulta imprescindible, por mor de la seguridad jurídica y por exigencia del principio de legalidad penal, la tipificación de las conductas de explotación laboral severa a las que puede conducir la trata de seres humanos (García Sedano, 2013, p. 129; Pomares Cintas, 2013, p. 139; y Villacampa Estiarte, 2014, p. 15).

\section{CONCLUSIONES}

A partir de las cuestiones analizadas en los apartados precedentes, a continuación se destacan las conclusiones más relevantes que dejan las puertas abiertas a futuras investigaciones.

Primera. La adaptación de la normativa española a los requerimientos internacionales y europeos en materia de trata de seres humanos supone un paso significativo para combatir esta práctica de forma efectiva y para diferenciarla de fenómenos afines. Ello no obstante, algunos aspectos del artículo 177 bis, como el elemento geográfico y la alusión a la nacionalidad de las víctimas, deben ser subsanados.

Segunda. El artículo 177 bis del Código Penal, al igual que la normativa internacional y regional de referencia, no menciona expresamente la "explotación laboral" 
como finalidad de la trata, sino que incorpora un conjunto de conductas - trabajo o servicios forzados, esclavitud, prácticas similares a la esclavitud, servidumbre, mendicidad- que denotan una dimensión laboral. Empero, el legislador no delimita el significado de estos términos. Más aún, en el Código Penal no se tipifican dichas conductas, salvo el empleo de menores de edad o de personas con discapacidad para la práctica de la mendicidad y la esclavitud como delito de lesa humanidad.

Tercera. Los delitos contra los derechos de los trabajadores tipificados en los artículos 311,311 bis y 312.2, segundo inciso, no pueden equipararse con las formas de explotación laboral enumeradas en el artículo 177 bis.

Cuarta. En aras de cumplir con el principio de legalidad penal, resulta indispensable la tipificación de las formas de explotación laboral mencionadas en el apartado 1.a) del artículo 177 bis del Código Penal.

\section{BIBLIOGRAFÍA}

Arrieta Idiakez, FJ., Manrique López, F. \& Manrique Rojo, F. (2011). Combating trafficking in human beings for labour exploitation in Spain. En Rijken, C. (ed.), Combating Trafficking in Human Beings for Labour Exploitation. Nijmegen: Wolf Legal Publishers.

Barrios Baudor, G.L. \& Quintanilla Navarro, R.Y. (2011). Derecho penal del trabajo en España: una visión panorámica. En VV.AA., Derecho penal laboral. Delitos contra los trabajadores. Montevideo: B de F.

Baucells Lladós, J. (2006). El tráfico ilegal de personas para su explotación sexual. En Rodríguez Mesa, M.J. \& Ruiz Rodríguez, L.R. (coord.), Inmigración y Sistema penal. Retos y desafíos para el siglo XXI. Valencia: Tirant lo Blanch.

Bonet Pérez, J. (2017). La interpretación de los conceptos de esclavitud y de otras prácticas análogas a la luz del ordenamiento jurídico internacional: aproximación teórica y jurisprudencial. En Pérez Alonso, E. (dir.), El Derecho ante las formas contemporáneas de esclavitud. Valencia: Tirant lo Blanch.

Canosa Usera, R. (2005). La prohibición de la esclavitud y del trabajo forzado: un ejemplo de integración entre tratados internacionales (art. 4 CEDH). En García Roca, J. \& Santolaya, P. (coord.), La Europa de los Derechos. El Convenio Europeo de Derechos Humanos. Madrid: Centro de Estudios Políticos y Constitucionales.

De Than, C. \& Shorts, E. (2003). International Criminal Law and Human Rights. Londres: Thomson.

De Vicente Martínez, R. (2008). Los delitos contra los derechos de los trabajadores. Valencia: Tirant lo Blanch.

García Arán, M. (2006). Introducción. En García Arán, M. (coord.), Trata de personas y explotación sexual. Granada: Comares. 
García Sedano, T. (2018). En las antípodas del trabajo decente: el trabajo forzoso. Lan harremanak: Revista de relaciones laborales, 39, 13-25.

García Sedano, T. (2013). La reforma del Código Penal español motivada por la trasposición de la Directiva 2011/36, sobre prevención y lucha contra la trata de seres humanos y protección de las víctimas. REJIE: Revista jurídica de investigación e innovación educativa, 8, 118-142.

González Ortega, S. (2010). El derecho de los extranjeros extracomunitarios en situación irregular a prestaciones de Seguridad Social derivadas de contingencias comunes. En González Ortega, S. (ed.), La protección social de los extranjeros en España. Valencia: Tirant lo Blanch.

Hortal Ibarra, J.C. (2015). Título XV. De los delitos contra los derechos de los trabajadores. En Corcoy Bidasolo, M. \& Mir Puig, S. (dirs.) \& Vera Sánchez, J. (coord.), Comentarios al Código Penal. Reforma LO 1/2015 y LO 2/2015. Valencia: Tirant lo Blanch.

Huici Sancho, L. (2008). La regulación internacional del trabajo. En Badia Martí, A.M. (dir.). Recopilación normativa sobre la Trata de personas, especialmente mujeres y niñas. Barcelona: Universitat de Barcelona.

Lascuraín Sánchez, J.A. (1997). Comentario al art. 312. En Rodríguez Mourullo, G. (ed.), Comentarios al Código Penal. Madrid: Civitas.

López Rodríguez, J. (2016). Conceptualización jurídica de la trata de seres humanos con fines de explotación laboral. Cizur Menor: Aranzadi-Thomson Reuters.

Manzanares Samaniego, J.L. (2010). Código Penal (Adaptado a la Ley Orgánica 5/2010, de 22 de junio). Comentarios y Jurisprudencia. Tomo II. Parte Especial (artículos 138 a 639). Granada: Comares.

Maraver Gómez, M. (2011). Capítulo XII. La trata de seres humanos. En Díaz-Maroto y Villarejo, J. (dir.), Estudios sobre las Reformas del Código Penal operadas por las LO 5/2010, de 22 de junio, y 3/2011, de 28 de enero. Cizur Menor: Aranzadi.

Montoya Melgar, A. (2011). Derecho del Trabajo. Madrid: Tecnos, Trigésima Segunda Edición.

Navas-Parejo Alonso, M. (2010). Actos de encuadramiento y cotización de los extranjeros extracomunitarios irregulares en el Régimen General. En González Ortega, S. (ed.), La protección social de los extranjeros en España. Valencia: Tirant lo Blanch.

Organización Internacional del Trabajo (2007). Eradication of forced labour. Ginebra: Conferencia Internacional del Trabajo, 96 $6^{\mathrm{a}}$ reunión.

Organización Internacional del Trabajo (2005). A global Alliance Against Forced Labour. Global Report under the Fellow-up to the ILO Declaration on Fundamental Principles and Rights at Work. Ginebra: Conferencia Internacional del Trabajo, $93^{\text {a }}$ reunión. 
Pérez Alonso, E. J. (2008). Tráfico de personas e inmigración clandestina (un estudio sociológico, internacional y jurídico-penal). Valencia: Tirant lo Blanch.

Pomares Cintas, E. (2013). El Derecho Penal ante la explotación laboral y otras formas de violencia en el trabajo. Valencia: Tirant lo Blanch.

Pomares Cintas, E. (2011). El delito de Trata de Seres Humanos con finalidad de explotación laboral. Revista Electrónica de Ciencia Penal y Criminología, 13.

Robertson, A.H. \& Merrills, J.G. (1993). Human Rights in Europe. A study of the European Convention on Human Rights. Manchester/New York: Manchester University Press, Tercera Edición.

Rodríguez-Piñero \& Bravo-Ferrer, M. (2011). La libertad de trabajo y la interdicción del trabajo forzoso. Relaciones Laborales: Revista crítica de teoría y práctica, 1, 3-16.

Sánchez-Covisa Villa, J. (2016). El delito de trata de seres humanos. Análisis del artículo 177 bis CP. Cuadernos de la Guardia Civil, Revista de Seguridad Pública, 52, 36-51.

Santana Vega, D. (2015). Título VII Bis. De la trata de seres humanos. En Corcoy Bidasolo, M. \& Mir Puig, S. (dirs.) y Vera Sánchez, J. (coord.), Comentarios al Código Penal. Reforma LO 1/2015 y LO 2/2015. Valencia: Tirant lo Blanch.

Sarasola Gorriti, S. (2009). Artículo 4. Prohibición de la esclavitud y del trabajo forzado. En Lasagabaster Herrarte, I. (dir.), Convenio Europeo de Derechos Humanos. Comentario Sistemático. Cizur Menor: Aranzadi, $2^{\underline{a}}$ edición.

Valle Muñiz, J.M. \& Villacampa Estiarte, C. (2004). Comentario al art. 312. En Quintero Olivares, G. (ed.), Comentarios al nuevo Código Penal. Cizur Menor: Aranzadi, Tercera Edición.

Vaz Cabral, G. (2006). La traite des êtres humains: réalités de l'esclavage contemporain. Paris: La Découverte.

Vieira Morante, F.J. (2007). Título XV. De los delitos contra los derechos de los trabajadores. En Conde-Pumpido Tourón, C. (ed.), Comentarios al Código Penal. Tomo 3. Barcelona: Bosch.

Villacampa Estiarte, C. (2017). El delito de trata de seres humanos en Derecho Penal español tras la reforma de 2015. En Pérez Alonso, E. (dir.), El Derecho ante las formas contemporáneas de esclavitud. Valencia: Tirant lo Blanch.

Villacampa Estiarte, C. (2014). Víctimas de la trata de seres humanos: su tutela a la luz de las últimas reformas penales sustantivas y procesales proyectadas. En InDret, Revista para el análisis del Derecho, 2.

Villacampa Estiarte, C. (2011a). Título VII Bis. De la trata de seres humanos. En Quintero Olivares, G. (dir.), Comentarios al Código Penal Español. Tomo I. Cizur Menor: Aranzadi, Sexta Edición.

Villacampa Estiarte, C. (2011b). El Delito de Trata de Seres Humanos. Una incriminación dictada desde el Derecho internacional. Cizur Menor: Aranzadi-Thomson Reuters. 